\title{
МОДЕЛИРОВАНИЕ ПРОЦЕССА ФОРМИРОВАНИЯ ПРОФЕССИОНАЛЬНОЙ СОЦИАЛИЗАЦИИ БУДУЩИХ РАБОЧИХ В УСЛОВИЯХ ОБРАЗОВАТЕЛЬНОГО ПРОСТРАНСТВА «ШКОЛА-КОЛЛЕДЖ-ПРЕДПРИЯТИЕ»
}

\section{MODELING OF THE PROCESS \\ OF FORMATION OF PROFESSIONAL SOCIALIZATION OF FUTURE WORKERS IN THE CONDITIONS OF THE EDUCATIONAL SPACE "SCHOOL-COLLEGE-ENTERPRISE"}

A. Zenkina

Summary: The article presents a structural and organizational model of the formation of professional socialization of future workers in the conditions of the educational space "school-college-enterprise», describes the relationship between the elements of the process of formation of professional socialization. The features and approaches of the formation of professional socialization of students, as well as the mechanisms of implementation of the structural and organizational model of the formation of professional socialization of future workers are considered.

Keywords: professional socialization, educational space, network interaction, a model of professional socialization of students, the pathway of professional development.

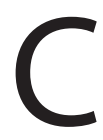
переходом от «материальной» к «знаниевой» экономике, внедрением высоких технологий и цифровизацией экономики меняется квалификационный профиль работников: возрастает потребность в новых компетенциях. Для успешного трудоустройства выпускник колледжа должен обладать способностью к личностному и профессиональному самосовершенствованию; высоким уровнем профессионально-личностных качеств, общей и профессиональной культурой; уверенностью в своих силах и способностью успешно презентовать себя как профессионала.

Формирование профессиональной социализации будущих рабочих в условиях образовательного пространства «школа-колледж-предприятие» - это целостный и непрерывный педагогический процесс, построенный в сформированном интегративном образовательном пространстве «школа-колледж-предприятие», на пересечении определяющих тенденций, таких как непрерывность образования, профессиональное самоопределение, возможность построения индивидуальных образовательных траекторий, и обеспечивающий гармонизацию
Зенкина Анжелика Владимировна
Директор, ОГБПОУ «Смоленский строительный колледж»
Zelika67@yandex.ru

Аннотация: В статье представлена структурно-организационная модель формирования профессиональной социализации будущих рабочих в условиях образовательного пространства «школа-колледж-предприятие», описаны взаимосвязи между элементами процесса формирования профессиональной социализации. Рассмотрены особенности и подходы формирования профессиональной социализации обучающихся, а также механизмы реализации структурно-организационной модели формирования профессиональной социализации будущих рабочих.

Ключевые слова: профессиональная социализация, образовательное пространство, сетевое взаимодействие, модель профессиональной социализации обучающихся, траектория профессионального развития. процесса образования, воспитания и деятельности обучающихся в процессе профессионального становления.

Профессиональная социализация будущих рабочих осуществляется посредством внедрения структурноорганизационной модели профессиональной социализации будущих рабочих в условиях образовательного пространства «школа-колледж-предприятие» с опорой на контекстный и компетентностный подходы. Данная модель (рисунок 1) обеспечивает поэтапное формирование социально-профессиональной компетентности выпускников профессиональных образовательных организаций на этапах школьного и студенческого периодов.

Структурно-организационная модель профессиональной социализации будущих рабочих в условиях образовательного пространства «школа-колледж-предприятие» представляет собой совокупность четырех структурных блоков: организационно-целевого, логикосодержательного, инструментально-технологического, оценочно-результативного. 

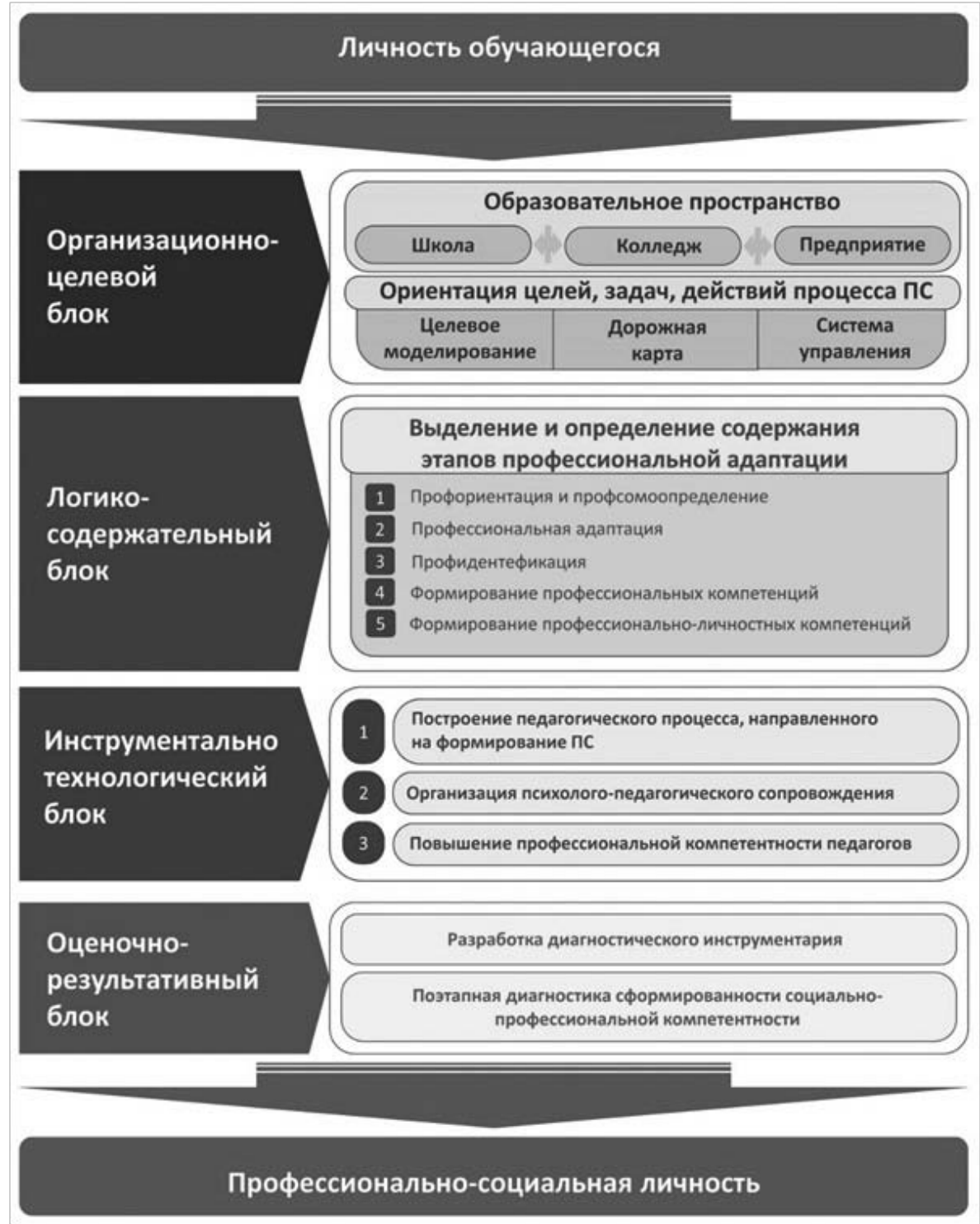

Рис. 1. Структурно-организационная модель профессиональной социализации будущих рабочих в условиях образовательного пространства «школа-колледж-предприятие»

Первый блок модели - организационно-целевой - позиционирует цели и задачи формирования профессиональной социализации будущих рабочих, обосновывает и определяет методы и формы построения педагогического процесса, определяет принципы и подходы сетевого взаимодействия между партнерами образовательного пространства «школа-колледж-предприятие». Системообразующими элементами данного блока являются целевое моделирование процесса формирования профессиональной социализации будущих рабочих в условиях образовательного пространства «школа-колледж-организация», организация взаимодействия партнеров образовательного пространства, создание системы управления данным пространством как основой профессиональной социализации будущих рабочих.

С помощью целевого моделирования определяются цели, структура, этапы формирования и система управления профессиональной социализацией в образовательном пространстве «школа-колледж-предприятие». Основные этапы целевого моделирования: определение целевого состояния (анализ текущего состояния кадровой потребности рынка труда, определение ключевых требований работодателя к выпускнику профессиональных образовательных организаций, изучение взаимовыгодных точек соприкосновения партнеров образовательного пространства, создание системы общего видения решения задач); разработка дорожной карты формирования образовательного пространства как основы профессиональной социализации будущих рабочих.

Для упорядочивания целей, задач, процессов формирования профессиональной социализации обучаю- 
щихся разрабатывается концепция целевого моделирования процесса формирования профессиональной социализации будущих рабочих в условиях образовательного пространства «школа-колледж-предприятие» (далее - Концепция). Основные разделы Концепции включают в себя:

1. анализ нормативных и отчетных материалов: стратегии развития Смоленской области до 2030 года; прогнозов востребованности кадров Смоленской области на период до 2024 года; официальных отчетов Департамента государственной службы занятости населения Смоленской области; анализа спроса и предложений в сегменте рынка труда «Строительство и ЖКХ»;

2. выявление проблемных ситуаций, определение их причин, задач, ожидаемых достижений;

3. дорожная карта создания педагогических условий, направленных на формирование успешной профессиональной социализации будущих рабочих.

Задачами целевого моделирования образовательного пространства «школа-колледж-предприятие» как основы профессиональной социализации обучающихся согласно Концепции стали:

- выстраивание в регионе сквозного межведомственного процесса подготовки кадров для региональной экономики; установление стратегического видения и определение возможности сетевых и стратегических партнеров для достижения единых целей в подготовке кадров для региона;

- добровольная кооперация и обмен ресурсами между участниками образовательного пространства. Интеграция кадровых, материально-технических и информационных ресурсов школы, колледжа, предприятия и их совместное использование обеспечит решение задач по подготовке кадров;

- создание совместных образовательных проектов, направленных на эффективную социализацию обучающихся;

- формирование единой системы мониторинга и разработка общих параметров, характеризующих качество образования, что позволит обеспечить доступность и повысить качество образования на всех уровнях и ступенях;

- интеграция информационных потоков, обеспечивающих основные виды деятельности органов управления образованием, в том числе и образовательных учреждений региона;

- создание эффективной системы управления образовательным пространством и его ресурсами.

Согласно Концепции для эффективной организации процесса формирования профессиональной социализации обучающихся в условиях образовательного про- странства «школа-колледж-предприятие» необходимо:

1. внедрение прогрессивных методов обучения и новых технологий, обеспечивающих трансформацию учебно-производственного процесса. Использование прогрессивных методов обучения требует культурной трансформации педагогического процесса в образовательных организациях, что повлечет за собой необходимость пересмотра учебных планов и программ с учетом новых вызовов, повышения квалификации педагогических работников, создание экосистемы образовательного пространства, позволяющей гибко реагировать на новые методы обучения и обеспечивающей творческое начало преподавательской деятельности. Особое место отводится цифровым технологиям, способствующим внедрению онлайн-обучения и непрерывного обучения.

2. обучение будущих рабочих реальным практическим навыкам и Soft- компетенциям в условиях опережающего обучения, что в дальнейшем обеспечит соответствие их профессиональной квалификации запросам экономики и поможет дальнейшему трудоустройству.

3. сотрудничество участников сети - ключевой фактор распространения эффективных решений и внедрение передовых технологий. Способность участников образовательного пространства к взаимовыгодному сотрудничеству в рамках решения единой цели обеспечит синергетический эффект совместных проектов.

4. создание системы оценки навыков на индивидуальном уровне в соответствии с запросами рынка труда, что дает возможность получить более четкую картину того, что обучающиеся должны знать и уметь для формирования у них необходимых компетенций, а также позволяет самому студенту контролировать свою собственную производительность.

5. гибкость и персонифицированность образовательных траекторий для обучающихся.

Созданные в условиях образовательного пространства «школа-колледж-предприятие» разнообразные образовательные траектории, направленные на эффективную социализацию обучающихся, являются достаточно гибкими, чтобы обеспечить динамику их развития и интерес к получению знаний. Не достаточно просто передать знания студенту, необходимо научить его как с помощью знаний улучшить свою жизнь, повысить профессиональные возможности, быстро адаптироваться в мире быстро развивающихся технологий.

В рамках создания образовательного пространства «школа-колледж-предприятие» организуется сетевое взаимодействие организаций, заинтересованных в вопросах подготовки кадров, что обеспечивает возможность реализации образовательных программ с 
использованием ресурсов данных организаций, расширяет возможности социализации обучающихся, преемственность между разными уровнями образования. Взаимодействие между партнерами строится на добровольной основе и удерживается общей проблематикой и интересами всех участников. Деятельность организаций образовательного пространства регламентируется локальными нормативными актами: положениями и регламентами о сетевом взаимодействии, договорами, программами, совместными планами. Данные документы определяют порядок взаимодействия, систему управления, обязанности партнеров и их ответственность, перечень мер по достижению общей цели и др. Наличие указанных локальных нормативных актов обеспечивает единые подходы к системе образования в отношении реализации образовательных программ и содержания образования на различных уровнях.

Мероприятия, направленные на формирование профессиональной социализации обучающихся в условиях образовательного пространства «школа-колледж-предприятие», представляются в Дорожной карте, которая содержит такие сведения, как наименование и группа мероприятий, сроки выполнения, значимые контрольные результаты, ответственные лица. Она позволяет структурировать отображения всех мероприятий формирования образовательного пространства, визуализировать взаимосвязи всех элементов, потребностей и технологий во времени, что обеспечивает эффективный переход к практической реализации полученного представления.

Основными направлениями Дорожной карты являются:

1. изучение количественной и качественной кадровой потребности организаций строительной, дорожно-строительной отраслей и сферы ЖКХ Смоленской области с целью определения набора профессиональных и личностных компетенций выпускника;

2. создание условий и реализация мероприятий, направленных на формирование профессиональной социализации обучающихся в условиях образовательного пространства «школа-колледжпредприятие», в том числе:

- мероприятия профориентационной направленности;

- мероприятия, способствующие повышению уровня профессиональной адаптации студентов к профессиональной деятельности и их профессиональной идентичности;

- мероприятия, направленные на повышение качества профессиональной подготовки;

- мероприятия, направленные на формирование профессионально-личностных качеств, необходимых в профессиональной деятельности.
3. мониторинг достижения показателей эффективности внедряемой педагогической модели профессиональной социализации обучающихся в условиях образовательного пространства «школа-колледж-предприятие».

Система управления образовательным пространством строится по кластерному принципу. Образовательно-производственный кластер - это профильное, добровольное объединение образовательных организаций, иных организаций, региональных органов исполнительной власти, создаваемое в целях межведомственного взаимодействия для решения задач в сфере обеспечения рынка труда региона квалифицированными рабочими кадрами, реализации современной эффективной корпоративной системы подготовки рабочих, создания инновационной системы непрерывного профессионального образования, реализации инновационных проектов на основе интеграции научного, образовательного и инновационного потенциала участников кластера. В состав образовательно-производственных кластеров, как правило, входят представители органов исполнительной власти, образовательных организаций, предприятий, профильных общественных организаций.

Высшим совещательным, экспертно-консультативным органом управления кластера является координационный совет, функциональными задачами которого выступают:

- разработка и утверждение стратегии развития образовательного пространства, направленного на формирование профессиональной социализации будущих рабочих;

- оценка эффективности реализованных мер достижения поставленных целей;

- рассмотрение вопросов организации деятельности участников образовательного пространства, направленного на формирование профессиональной социализации будущих рабочих;

- разработка и утверждение плана работы кластера в рамках деятельности образовательного пространства «школа-колледж-предприятие»;

- организация взаимоотношения с государственными органами, юридическими и физическими лицами по вопросам подготовки кадров.

Логико-содержательный блок структурно-организационной модели формирования профессиональной социализации в условиях образовательного пространства «школа-колледж-предприятие» опирается на выделение основных этапов профессиональной социализации обучающихся: профессиональной ориентации и самоопределения школьников, профессиональной адаптации студентов к профессиональной деятельности, профессиональной идентификации, формирования профессиональных и профессионально-личностных компетенций. 
В рамках профориентационной деятельности и профессионального самоопределения школьников создается сеть консультационной навигации и информирования школьников и их родителей о состоянии и перспективах рынка труда, о возможностях профессиональных образовательных организаций; организуется профильное обучение школьников; проводятся массовые профориентационные мероприятий различной направленности (специализированные конкурсы, мастер-классы, вортшопы, тренинги и др.).

Профессиональная адаптация студентов к профессиональной деятельности нами рассматривается как процесс знакомства, изучения и приспособления индивида к особенностям избранной им профессии, к условиям производства, к взаимодействию с профессионалами, работающими в условиях реального производства. При этом суть и назначение адаптационной функции заключаются в изменении внутренних условий для приспособления к внешним условиям и наоборот.

Профессиональная адаптация студентов к профессиональной деятельности содержит три основных этапа: ознакомительный, действенно-ориентационный, фукционально-ассимиляционный.

Ознакомительный этап, как правило, проходит на первом курсе и включает в себя комплексную работу по знакомству обучающихся с производственной средой, воспитание у них интереса к выбранной сфере деятельности, формирование мотивации к овладению данной профессией. На действенно-ориентационном этапе (2-й курс обучения) проводится формирование общепроизводственных знаний и закрепление их в производственных мастерских колледжа, профессиональных компетенций, выполнение конкретных производственных задач, курсовых работ. Развитие личностных качеств будущего рабочего, необходимых для успешной профессиональной адаптации к производственным условиям, происходит в течение всего времени обучения в рамках урочной и внеурочной деятельности в форматах специальных курсов, например, «Коммуникабельность и карьера», «Готовность к профессиональной деятельности» и т.п. Фукционально-ассимиляционный этап (выпускной курс обучения) включает в себя самостоятельную деятельность студента, свободное и активное участие в функционировании производственной среды.

Профессиональная идентификация позволяет обучающимся отождествлять себя с представителями своей будущей деятельности. «Механизмом идентификации является сопоставление образов, ценностей, интересов, взглядов, оценок, моделей поведения, принятых в группе с теми, которые не включены в свою общность» [3]. «Функциями профессиональной идентификации являются: формирование и обеспечение стабильности профессионального Я индивида; профессиональное раз- витие человека и его профессиональная социализация; регуляция профессионального поведения» [2].

Процесс формирования профессиональных компетенций представляет собой подготовку обучающегося к самостоятельному выполнению основных видов профессиональной деятельности и профессиональных задач в условиях производства. Состав профессиональных компетенций будущего рабочего должен соответствовать требованиям работодателей и регионального рынка труда, что исключит период «доучивания» на производстве и позволит с первых дней работы включиться в самостоятельную работу.

Формирование профессиональных компетенций в образовательной организации происходит на всех этапах учебно-производственного процесса в соответствии с Федеральным государственным образовательным стандартом и основной образовательной программой по профессии. Условно профессиональные компетенции можно разделить на когнитивную и деятельностную составляющие. Когнитивная составляющая включает в себя актуальность, объем профессиональный знаний, умение переносить эти знания на решение производственных задач; деятельностная - умения и навыки, необходимые для качественного выполнения практических заданий и работ по выбранной профессии.

Для формирования профессиональных умений и навыков у обучающихся, накопления у них первоначального опыта будущей профессиональной деятельности необходимо в учебно-производственном процессе использовать активные методы обучения (проблемное обучение, проектную деятельность, производственно-технологические ситуации и др.).

Развитие у обучающихся профессионально-личностных качеств (компетенций), как правило, происходит посредством реализации программы профессионального воспитания, которая является неотъемлемой частью основной профессиональной образовательной программы. Задачами данной программы являются:

- формирование личностных качеств, способствующих успешной профессиональной социализации обучающихся;

- развитие интереса к будущей профессии;

- формирование умения самостоятельно и осознанно принимать решения, планировать свою профессиональную карьеру;

- воспитание чувства ответственности за конечный результат.

Важными составляющими программы профессионального воспитания являются:

1. организация учебно-производственного процесса в соответствии с задачами программы (создание условий для профессионального воспитания 
обучающихся, учет их индивидуальных особенностей, включение в учебный план факультативных предметов, организация исследовательской и проектной деятельности и т.д.);

2. организация воспитательной работы, направленной на формирование профессионально-личностных компетенций, необходимых для профессионального становления будущих рабочих (создание условий для формирования инициативности, самостоятельности, толерантности и других личностных качеств, проведение конкурсов, реализация социально-значимых проектов и др.);

3. организация методической работы, направленной на формирование профессионально-личностных компетенций (повышение квалификации преподавателей, организация исследовательской работы обучающихся и преподавателей по заявленной проблеме и т.д.).

Также в рамках логико-содержательного блока структурно-организационной модели профессиональной социализации будущих рабочих выделены основные компоненты профессиональной социализации (ценностно-мотивационный, коммуникативный, когнитивный, деятельностный), направленные на формирование у обучающихся социально-профессиональных компетенций.

Данные компоненты отображают необходимость реализации взаимообусловленных и взаимодополняющих функций:

1. смыслообразующая, придающая профессиональной социализации глубокий личностный смысл, способствующая полной включенности обучающегося в процесс профессионального развития, осознания роли учебной и трудовой деятельности, знания и принятие социальных норм и правил поведения. Ценностно-мотивационный компонент определяет «становление профессионального сознания будущих рабочих как систему установок, характеризующих личностно-значимое отношение их к профессии, эмоциональноценностное отношение к себе как личности и профессионалу, к социальным ценностям командной работы, выступающих регулятором поведения личности как субъекта профессиональной деятельности» [1];

2. продуктивно-созидательная функция, обеспечивающая нацеленность педагогических влияний на поэтапную трансформацию учебно-познавательной деятельности в профессиональную в контексте самоидентификации студента с определенными ценностями, поведением, образом социально-профессионального сообщества; формирование умений и навыков использования накопленного диапазона знаний и опыта при решении типичных и нестандартных социально- профессиональных задач; построение оптимальных образовательных стратегий для достижения успешности в профессиональной деятельности и жизни в обществе, самосовершенствования и саморазвития;

3. информационно-коммуникативная функция состоит в получении и обработке информации, обмене ее между индивидами, построении взаимоотношений между людьми. Данная функция позволяет находить, анализировать, систематизировать, передавать значимую для профессионального развития информацию, а также использовать ее в своей учебно-производственной деятельности; передавать и получать данную информацию, при этом формируя свой профессиональный и личностный опыт, понимать и принимать взгляды и установки собеседника, достигать определенной согласованности во взглядах или получать новые результаты, строить взаимовыгодное общение, организовывать совместную деятельность.

Инструментально-технологический блок структурно-организационной схемы профессиональной социализации будущих рабочих включает в себя организацию педагогического процесса с использованием возможности образовательного пространства «школа-колледжпредприятие». Эффективность формирования профессиональной социализации обучающихся в создаваемом образовательном процессе опирается на совокупность педагогических условий: построение педагогического процесса, способствующего поэтапной трансформации учебно-познавательной деятельности обучающихся в профессиональную; организация психолого-педагогического сопровождения профессиональной социализации; повышение профессиональной компетентности педагогов и других участников образовательного процесса.

Оценочно-результативный блок структурно-организационной модели формирования профессиональной социализации будущих рабочих включает в себя разработку диагностического инструментария профессиональной социализации обучающихся и поэтапную ее диагностику.

Таким образом, внедрение структурно-организационной модели обеспечивает целостность и актуальность процесса формирования профессиональной социализации будущих рабочих в условиях образовательного пространства «школа-колледж-предприятие» и способствует поэтапному формированию у обучающихся общеобразовательных и профессиональных образовательных организаций личностных, социальных, профессиональных компетенций, востребованных современным обществом. 


\section{ЛИТЕРАТУРА}

1. Горшенин В.И. Социокультурная среда образовательной организации как средство профессиональной социализации будущего специалиста среднего звена: Диссертация. Оренбург, 2017.

2. Ефремов Е.Г. Особенности формирования профессионального самосознания на различных стадиях профессионального обучения (На примере студентов-психологов) [Текст]: дис. канд. психол. наук / Е.Г. Ефремов. — Томск, 2000.-186 с.

3. Копыця Е.А. Профессиональная социализация студентов в ССУЗе: сущность и подходы // Новые технологии. 2011. №1. URL: https://cyberleninka.ru/ article/n/professionalnaya-sotsializatsiya-studentov-v-ssuze-suschnost-i-podhody (дата обращения: 10.11.2020).

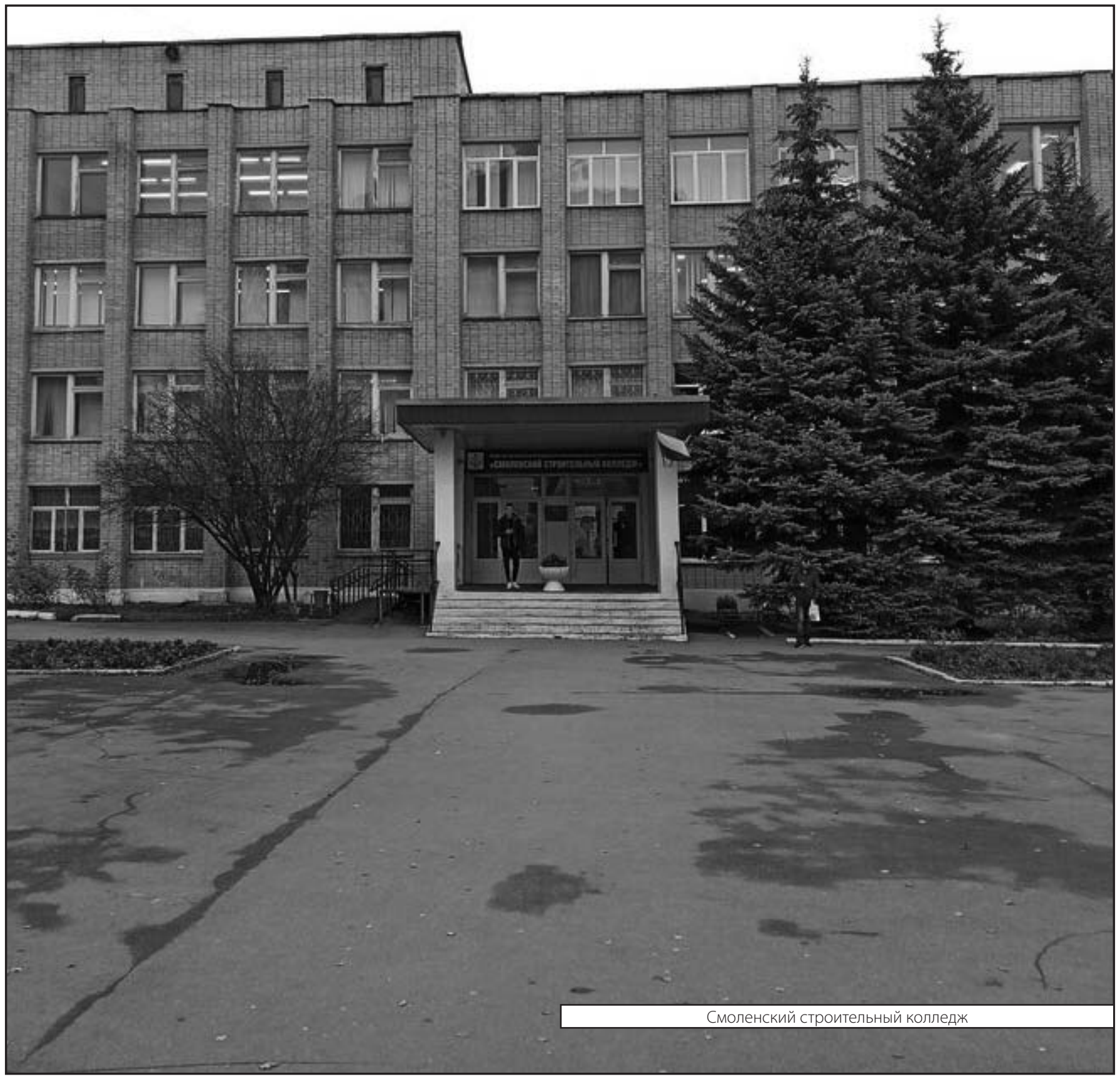

